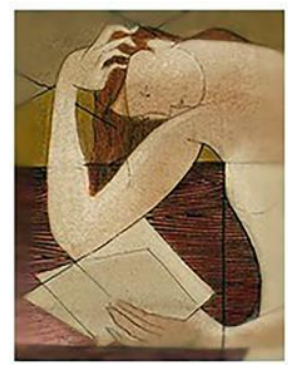

Nau Literária

crítica e teoria da literatura em língua portuguesa

PPG-LET UFRGS

ISSN 1981-4526

https://seer.ufrgs.br/NauLiteraria

Vol.16, n. 2 -2020

Dossiê Literatura e Gênero

MORRISON, Toni. A origem dos outros: seis ensaios sobre racismo e literatura. São Paulo: Companhia das Letras, 2019. 152 p.

\title{
Toni Morrisson e a origem dos outros
}

Luiz Mauricio Azevedo da Silva ${ }^{1}$

Merece nota a chegada de um volume de textos da norte-americana Toni Morrison (1931-2019), laureada com o Nobel de Literatura no ano de 1993, ao mercado brasileiro. A edição brasileira tem qualidades evidentes: conta com prefácio de Ta-Nehisi Coates (que se tornou uma personalidade central na discussão da causa racial estadunidense ao lançar, em 2015, o intrigante Between the world and me - espécie de revisão criativa de um clássico da tradição afro-americana crítica, o dissonante The fire next time, de James Baldwin, sobre o racismo nos Estados Unidos); possui capa dura e cinta auxiliar produzida por Alceu Chiesorin Nunes, a fim de não poluir a belíssima ilustração de Kara Walker ${ }^{2}$. A tradução é por conta de Fernanda Abreu, que é formada em História, na Universidade Paris I Panthéon-Sorbonne, e possui mestrado em Sociologia, na UFRJ. O conjunto desses elementos confere uma evidente sensação de solenidade à edição, em consonância com o status internacional da autora, mas oferece também um grande e necessário esforço da editora Companhia das Letras em produzir familiaridade com o tom ensaísta e combativo que Morrison lança mão, bem incomum ao mercado editorial brasileiro.

Há um enorme risco de que, ao se despir o fazer-literário de sua suposta áurea mágica de produção (o que é inegavelmente positivo), talvez não se consiga evitar que na operação de desvelamento da natureza material da literatura ocorra, seja por desencanto ou má-fé, a reificação do acontecimento literário aos olhos de quem promove sua mercantilização. Essa discussão, aparentemente deslocada do objeto dessa resenha é, pois, o ponto central de $A$ origem dos outros: seis ensaios sobre racismo e literatura. É, afinal, a relação entre o fazer-

\footnotetext{
${ }^{1}$ Pós-doutorando no Departamento de Letras Clássicas e Vernáculas, USP.

2 Trata-se de uma reprodução de um dos trabalhos da mostra The gross clinician presents: Pater Gravidam, de Kara Walker. Todos os livros de Toni Morrison, relançados no Brasil pela editora Companhia das Letras, a partir de 2018, contam com capas resultantes de ilustrações da artista plástica californiana.
} 


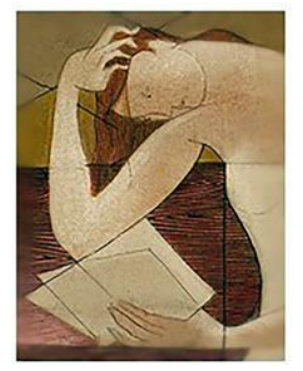

literário e a sociedade civil o assunto de Toni Morrison nessa publicação. São no total seis ensaios: romantizando a escravidão; ser ou tornar-se o estrangeiro; o fetiche da cor; configurações da negritude; narrar o outro; o lar do estrangeiro. Com um tom predominantemente metalinguístico, A origem dos outros: seis ensaios sobre racismo e literatura trata de uma certa negociação discursiva de cunho duplamente articulada, na qual a parte receptora demonstra solidariedade ao esforço do emissor, auxiliando no entendimento da mensagem. Esse paradigma crítico-literário estabelecido pela autora tem profundas raízes teóricas, é fruto tanto de uma sólida formação acadêmica (Morrison era mestre em Literatura, pela Universidade de Cornell), quanto de uma longa carreira na área editorial (foi produtora editorial da Random House). O uso dessas ferramentas aparece no ensaio "o lugar do estrangeiro", no qual Morrison esboça o que pode ser tomado como um tratado de criação literária e de reconstrução dos elementos formadores de sua própria tradição literária. A África aparece ali não mais como um conceito escapista para fantasias racialistas, e sim como um território com características bem específicas, mediadas por um texto que dá preferência a um fator estético, ao uso das palavras, ao esmero estilístico. Nesse sentido, é como se a expectativa de exotismo da Morrison-leitora fosse frustrada, mas imediatamente substituída pelo flagrante de que a literatura africana pode reservar atributos maiores do que o imperativo ético de sabermos de sua existência. Não seria imprudente sugerir que parte dos leitores brasileiros sentem o mesmo ao se depararem com a literatura da autora.

Um dos maiores entraves para a recepção das obras da autora no Brasil tem sido uma certa frustração em relação às expectativas que sua obra - tanto crítica quanto ficcional - traz. Por ser mulher e negra, em tempos de hipervalorização da imagem dos escritores, seria aceitável esperar que Morrison acenasse com condescendência a um eventual leitor iniciante, sedento por encontrar na crítica literária o acerto de contas histórico que não encontra fora dela. Contudo, como escritora habilidosa que é, ela aceita o alto preço que uma reflexão intelectualmente corajosa impõe, e se afasta das soluções simples, das adulações endogâmicas, e da militância de ocasião. Seu pensamento toma o aspecto de uma práxis negra resultado de uma sofisticada formação teórica e uma incomum disposição para o combate das condições materiais que circundam sua classe de origem. 


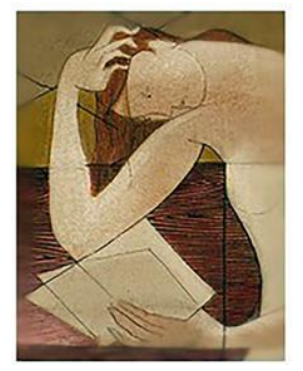

Nau Literária

crítica e teoria da literatura em língua portuguesa

PPG-LET UFRGS

ISSN 1981-4526

https://seer.ufrgs.br/NauLiteraria

Vol.16, n. 2 -2020

Dossiê Literatura e Gênero

O tom da obra é de um diálogo franco, direto, com o leitor; há uma proposta epistotar subjacente no texto. A propósito: a manipulação do formato epistolar como forma de estabelecer um leitor-ideal é uma forma narrativa bastante explorada pela autoria negra estadunidense. Em certa medida, essa operação permite aos autores um tipo de solenidade e de quebra reveste o texto ao status de testemunho. Pouco provável que essa tendência não tenha relação com as narrativas de escravidão, primeiros textos publicados em território norteamericano por indivíduos negros, por volta do ano de 1746. O circuito por onde essas obras circulavam incluía um público disposto a acolhê-las e uma entidade editorial disposta a editálas. No campo da recepção, essas mensagens tinham objetivo político declarado: o de conscientizar o conjunto das comunidades não-negras a apoiarem iniciativas e leis que tivessem como objetivo a emancipação de seus escravizados. Era, pois, uma literatura carregada com consciência - e certo orgulho - de sua instrumentalidade radical, o que nos remete à renitente questão das limitações históricas da autoria literária. Fosse um livro sobre o registro de um tempo específico, essas questões seriam centrais na obra; entretanto, trata-se de um exercício de reflexão da atividade literária que, embora tenha dentro de si a polpa do social, é um pouco mais que o mero registro de uma época. A literatura opera dentro da história e ajuda ela mesma a construir o fato histórico, transformando-a constantemente. Uma de suas múltiplas potências é sugestionar a percepção da realidade prática do presente à falsificação do passado, como forma de garantir a hegemonia das narrativas históricas no presente. É por isso que Morrison defende que "uma das maneiras de que as nações dispunham para tornar palatável o caráter degradante da escravidão era a força bruta; outra era a romantização" (MORRISON: 2019, p. 27.). Essa declaração com feições de acusação faz parte de um esforço para desconstrução da narrativa sobre a escravidão em território norteamericano. Segundo a autora, há uma crença na existência de uma natureza comum a todos os negros, um essencialismo rústico. Como prevaleceu a abolição, inclusive com Abraham Lincoln condecorando a autora Harriet Beecher Stowe, passou também a contar a versão de que o problema eram os maus tratos aos escravos. A escravidão precisava ser abolida, porque teria se mostrado insuficiente para dar conta de proteger os escravizados dos excessos de alguns senhores. A lógica protetiva desse caso era de que o próprio processo de escravização 


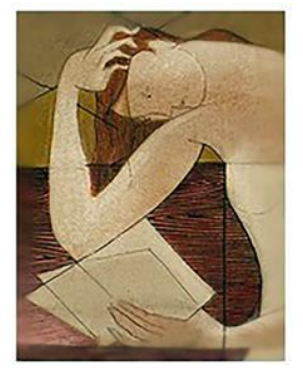

ampliava os riscos de excesso e era o excesso de episódios de maltratos - e não a reificação em si - o problema.

Harriet Beecher Stowe não escreveu A cabana do Pai Tomás para Tom, tia Chloe ou qualquer pessoa negra ler. Seus leitores contemporâneos eram pessoas brancas, aquelas que precisavam, queriam ou conseguiam apreciar a romantização (MORRISON: 2019, p.36).

O enfrentamento direto de grandes vultos literários não é algo usual na tradição crítica brasileira de autores. Por essa razão, logo no começo desse texto, chamei atenção para o paralelo entre criação literária e crítica literária, simbolizado pela problematização do comportamento das oficinas de criação literária no Brasil. Um mercado editorial raquítico, unívoco e predominantemente não-negro produz uma literatura - e infelizmente uma crítica literária - de configuração igualmente frustrante. Nossos autores raramente se mostram dispostos a posicionarem suas produções em relação à tradição sociológica que os formaram e - quando fazem - carecem de uma formação intelectual que os possibilite escapar do eterno nós versus eles, no qual a ignorância sobre as produções periféricas é substituída por um projeto de defesa da ignorância sobre as produções centrais.

Um dos objetivos do racismo científico é identificar um forasteiro de modo a definir a si mesmo. Outra possibilidade é a manutenção (ou mesmo o gozo) da própria diferença sem desprezo pela diferença categorizada do Outremizado. A literatura é especialmente e evidentemente reveladora ao expor/refletir sobre a definição de si, quer condene ou apoie o modo pelo qual ela é adquirida. Como uma pessoa se torna racista ou sexista? Já que ninguém nasce racista, e tampouco existe qualquer predisposição fetal ao sexismo, aprende-se a Outremização não por meio do discurso ou da instrução, mas pelo exemplo. (MORRISON, 2019, p. 17).

Dentre as muitas vítimas de uma guerra simbólica está a presunção de que todo conflito social se resolveria mediante um exercício de boa-vontade das partes envolvidas. $\mathrm{Na}$ literatura, isso costuma resultar em obras que emulam o discurso do outro para que assim possa se continuar a falar dos mesmos agentes de sempre. É dessa árvore que brotam oxímoros dolorosos, exemplificados pela sucessão de episódios em que se apresenta uma literatura documentada como sendo indianista, mas que na verdade é colonialista; ou mesmo na presunção desidradata de sentido material de que a produção estética de Jorge Amado seria literatura negra.

Durante muito tempo, entretanto, pareceu mais difícil para nós, brasileiros, entender o peso dessas discussões. Como nação apostou-se no mito da democracia racial e a literatura 


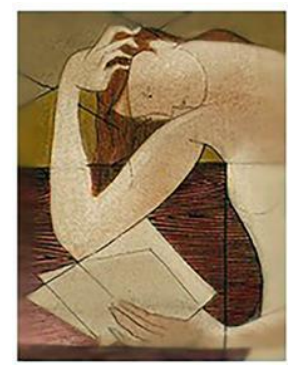

sempre esteve lá para dar sua contribuição ${ }^{3}$. Assim, A origem dos outros: seis ensaios sobre racismo e literatura é uma oportunidade editorial rara para examinarmos as estruturas ficcionais da nossa formação histórica. Mais do que uma chaga na história pessoal das vítimas, o racismo produz uma fenda profunda no tecido social, deformando nosso ideal de civilização. Uma Nobel de literatura sabe bem a extensão desse dano, mas espanta que presumamos que sua capacidade de ver com clareza o que não temos visto venha do fato de ter nascido negra e não do acidente existencial de ter sido vítima do brutal processo racialista a que submetemos, como sociedade, a comunidade negra.

\section{Referências}

BALDWIN, James. The fire next time. Nova York: Dial Press, 1963.

BERND, Zilá. Negritude e literatura na América Latina. Porto Alegre: Mercado Aberto, 1987.

COATES, Ta-Nehisi. Between the world and me. Nova York: Spiegel \& Grau, 2015.

MORRISON, Toni. A origem dos outros: seis ensaios sobre racismo e literatura. São Paulo: Companhia das Letras, 2019.

\footnotetext{
${ }^{3}$ Houve certo receio em algumas produções teóricas em abarcar a interpretação estadunidense. Em certa medida porque os Estados Unidos pertenciam a um campo ideológico reconhecido como anti-latino; mas muito porque o reconhecimento das demarcações étnicas não parecia oferecer ganho algum para a parte não-negra dessa história: "Esta epidermização da questão feita por alguns críticos nos parece inoperante por não haver nenhuma relação entre o fato de se pertencer a determinada etnia e a estruturação da sensibilidade" (BERND, 1987, p. 16).
} 